\title{
Crisis Resources for Emergency Workers (CREW II): results of a pilot study and simulation-based crisis resource management course for emergency medicine residents
}

\author{
Christopher M. Hicks, MD, MEd*; Alex Kiss, $\mathrm{PhD}^{\dagger}$; Glen W. Bandiera, MD, MEd*; \\ Christopher J. Denny, BA, MD, MSc, DABEM ${ }^{\ddagger}$
}

\section{ABSTRACT}

Objectives: Emergency department resuscitation requires the coordinated efforts of an interdisciplinary team. Aviationbased crisis resource management (CRM) training can improve safety and performance during complex events. We describe the development, piloting, and multilevel evaluation of "Crisis Resources for Emergency Workers" (CREW), a simulation-based CRM curriculum for emergency medicine (EM) residents.

Methods: Curriculum development was informed by an a priori needs assessment survey. We constructed a 1-day course using simulated resuscitation scenarios paired with focused debriefing sessions. Attitudinal shifts regarding team behaviours were assessed using the Human Factors Attitude Survey (HFAS). A subset of 10 residents participated in standardized pre- and postcourse simulated resuscitation scenarios to quantify the effect of CREW training on our primary outcome of CRM performance. Pre/post scenarios were videotaped and scored by two blinded reviewers using a validated behavioural rating scale, the Ottawa CRM Global Rating Scale (GRS).

Results: Postcourse survey responses were highly favourable, with the majority of participants reporting that CREW training can reduce errors and improve patient safety. There was a nonsignificant trend toward improved teambased attitudes as assessed by the HFAS ( $p=0.210)$. Postcourse performance demonstrated a similar trend toward improved scores in all categories on the Ottawa GRS ( $p=0.16)$.

Conclusions: EM residents find simulation-based CRM instruction to be useful, effective, and highly relevant to their practice. Trends toward improved performance and attitudes may have arisen because our study was underpowered to detect a difference. Future efforts should focus on interdisciplinary training and recruiting a larger sample size.

RÉSUMÉ

Objectif: La réanimation aux services des urgences nécessite la coordination des efforts d'une équipe interdisciplinaire. La formation donnée sur la gestion des ressources en situation de crise (GRSC), empruntée au domaine de l'aviation, peut améliorer la sécurité et le rendement au cours d'événements graves. Nous faisons état ici de l'élaboration, de la conduite, et de l'évaluation à plusieurs niveaux du cours "Crisis Resources for Emergency Workers "(CREW), un cours de GRSC, axé sur la simulation et conçu à l'intention des résidents en médecine d'urgence (MU).

Méthodes: Le contenu du cours a été élaboré à partir d'une évaluation préalable des besoins, faite par enquête. Nous avons préparé un cours d'une journée, fondé sur des mises en situation de réanimation, et complété par des séances de bilan ciblées. Les changements d'attitude en ce qui concerne le comportement des équipes ont été évalués à l'aide du questionnaire Human Factors Attitude Survey (HFAS). Un sous-groupe de 10 résidents a participé à des simulations communes de réanimation, avant et après le cours, afin de quantifier l'effet du cours CREW sur le principal critère d'évaluation, soit le rendement de la GRSC. Les mises en situation ont été filmées avant et après le cours, puis cotées par deux observateurs tenus dans l'ignorance de l'ordre des scénarios, à l'aide d'une échelle validée d'évaluation du comportement, l'Ottawa CRM Global Rating Scale (GRS).

Résultats: Les réponses à l'enquête après le cours étaient très favorables, la majorité des participants ayant indiqué que la formation CREW pouvait diminuer les erreurs et améliorer la sécurité des patients. L'HFAS a révélé une

From the *Division of Emergency Medicine, University of Toronto, St. Michael's Hospital; Institute for Clinical and Evaluative Sciences, Sunnybrook Health Sciences Centre; and $\ddagger$ Division of Emergency Medicine, University of Toronto, Sunnybrook Health Sciences Centre, Toronto, ON.

Correspondence to: Dr. Christopher Hicks, Division of Emergency Medicine, University of Toronto, St. Michael's Hospital, 1-008e Shuter Wing, 30 Bond Street, Toronto, ON M5B 1W8; christopher.hicks@utoronto.ca.

This article has been peer reviewed. 
tendance non significative à l'amélioration des attitudes d'équipe ( $p=0.210)$. II est également ressorti de l'évaluation du rendement, après le cours, une tendance similaire à I'amélioration des résultats dans toutes les catégories, sur l'échelle d'Ottawa ( $p=0.16$ ).

Conclusions: Les résidents en MU ont trouvé la formation GRSC axée sur la simulation utile, efficace, et très pertinente. Peut-être s'est-il dégagé une tendance à l'amélioration du rendement et des attitudes parce que l'étude n'était pas suffisamment puissante pour détecter des différences. Les recherches futures devraient surtout porter sur la formation interdisciplinaire et reposer sur un échantillon de plus grande taille.

Keywords: crisis resource management, medical education, patient safety
The emergency department (ED) is a dynamic and potentially hazardous patient care environment. High volume and acuity, diagnostic ambiguity, stress, fatigue, and frequent interruptions and distractions challenge decision making and pose barriers to effective team performance during critical events. ${ }^{1,2}$ Reviews of hospital safety suggest that the majority of adverse events are nontechnical in nature, stemming from failures in team communication, situational awareness, resource utilization, and leadership. ${ }^{3,4}$ Tasks that require divided attention, such as a complex trauma resuscitation or managing multiple patients, are particularly vulnerable to medical error at both the individual and the team level. ${ }^{5-7}$ Training strategies targeting only knowledge or procedural skills are likely insufficient to detect and mitigate consequential medical error during complex and rapidly evolving events. Team-based strategies are also required.

The study of aviation safety and high-reliability organizations (HROs) has led to the development of simulation-based crisis resource management (CRM) training for medical teams., High-fidelity human patient simulation using a full-sized, computercontrolled manikin situated in a realistic, immersive environment allows for deliberate practice with focused feedback on performance and promotes the transfer of nontechnical skills to the clinical domain while posing no threat to patients. ${ }^{10,11}$ Anesthesia CRM training has been shown to improve team performance and decrease error during medical and surgical crises in the operating room. ${ }^{12,13}$ Building on this success, preliminary work has been undertaken to develop CRM applications for other areas of acute care medicine, notably critical care and emergency medicine (EM-CRM). ${ }^{14}$ Despite its potential impact on safety and error, there is currently no formally evaluated or systematically derived CRM curriculum for emergency medicine (EM) postgraduate (resident) trainees in Canada.
Creating effective CRM training programs begins with an a priori team task analysis to define specific training objectives. ${ }^{15}$ The impact of instruction should then be evaluated in a systematic fashion to verify that training objectives have been met. A popular framework for guiding program evaluation, the Kirkpatrick typology, examines the impact of training on four hierarchical levels: participant reaction, learning, behaviours (extent of performance change), and results (impact on organizational effectiveness). ${ }^{16}$ Salas and colleagues argued that effective CRM training should demonstrate a positive influence on multiple levels of the Kirkpatrick typology, with a particular emphasis on improved team behaviours and organizational effectiveness. ${ }^{17}$

In this second phase of the Crisis Resources for Emergency Workers (CREW) project, we describe the development, piloting, and evaluation of a novel, simulation-based EM-CRM curriculum for Canadian EM residents using the Kirkpatrick typology as a framework to structure a multilevel assessment. The objectives of this pilot study were to evaluate the feasibility of CREW training (primary outcome) and identify shifts in team-based behaviours and attitudes (secondary outcomes).

\section{METHODS}

\section{Curriculum design}

The CREW curriculum format, content, and training objectives were informed through integration of data from two sources: a structured literature review and an a priori team task analysis. The literature review queried multiple databases in medicine, allied health, and high-risk industry regarding best practice guidelines for simulation-based CRM training. The team task analysis consisted of a previously reported needs assessment survey of EM staff physicians, residents, 
and nurses at two Toronto teaching hospitals (CREW I). ${ }^{18}$ CREW I helped define EM team training objectives by outlining how core CRM principles should be modified to suit domain-specific needs. The CREW II course structure and objectives were subsequently derived from aviation and anesthesia CRM and given an EM context through our needs assessment survey (Table 1).

CREW II was a full-day event for all residents enrolled in the 5-year Royal College of Physicians and Surgeons of Canada EM program at the University of Toronto. The course took place at the Canadian Simulation Centre for Human Performance and Crisis Management Training at Sunnybrook Health Sciences Centre in Toronto. The training had two components: precourse learning and a full-day simulation-based exercise. The precourse manual was developed by two CREW II study authors (C.M.H., C.J.D.) and

\begin{tabular}{l} 
Table 1. Nontechnical skills emphasized in CREW \\
Leadership skills \\
Stays calm and in control during crises \\
Prompt and firm decision making \\
Maintains global perspective ('big picture"') \\
Recognizing authority gradients \\
Situational awareness \\
Avoids fixation errors \\
Reassesses and reevaluates situation constantly \\
Anticipates likely events \\
Communication skills \\
Communicates clearly and effectively \\
Uses directed verbal/nonverbal communication \\
Listens to team input \\
Interdisciplinary and interprofessional communication \\
Problem solving \\
Organized and efficient problem-solving approach \\
Quick in implementation (concurrent management) \\
Considers alternatives during crisis \\
Resource utilization \\
Calls for help appropriately \\
Prioritizes and reprioritize tasks appropriately \\
Triage \\
Error and cognition \\
Nature and genesis of common cognitive pitfalls (fixation, \\
premature closure, satisficing) \\
Heuristics and biases \\
Stress and fatigue \\
Recognizing and managing the impact of stress on individual \\
and team performance \\
Cycling team members, accommodating for fatigue \\
CREW = Crisis Resources for Emergency Workers. \\
\hline
\end{tabular}

distributed to participants 2 weeks before the course. The manual contained an introduction to EM-focused team training and human factors theory, the elements of CRM, cognition and error theory, and stress and its effects on performance during critical events. The CREW II course began with a group review of the precourse content, as well as a general course overview and orientation to the simulator. Four small groups of three to four residents per group were paired with an instructor with expertise in CRM and simulation. The four instructors (two emergency physicians and two anesthesiologists) met with the study authors prior to the course to discuss goals and objectives and refine the scenarios.

The simulation component of CREW II consisted of the four small groups rotating through four resuscitation scenarios adapted from the Society for Academic Emergency Medicine Online Simulation Case Library and modified using a template developed by Deikmann and Rall to emphasize one or two key EM-specific CRM team behaviours per scenario. ${ }^{19,20}$ Each resident had the opportunity to act as team leader for at least one scenario, with the remainder of the group assigned to various roles as members of the health care team playing a specific confederate role. Two scenarios took place in a high-fidelity simulation environment (SimMan Advanced Patient Simulator Version 3.4, Laredal Medical Canada, Toronto, ON) and two in a lower-fidelity simulation environment that included a full-body intubatable manikin (Resusci Anne Advanced Skill Trainer, Laredal Medical Canada), a heart rhythm generator (HeartSim 3000, Laredal Medical Canada), and basic resuscitation equipment in a classroom adjacent to the simulation centre. All scenarios underwent pilot testing and revision prior to the course based on feedback from the simulation team. Each scenario lasted a maximum of 15 minutes and was paired with a 25 -minute formal debriefing session led by the instructor, focusing on nontechnical and team-based teaching points specific to the case (Table 2). Together, the four scenarios covered the breadth of the EM-focused CRM training objectives identified defined by our team task analysis.

Institutional research ethics approval for the CREW II course and informed consent from all participants were obtained. We collected basic demographic information on participants regarding their level of training, resuscitation experience, and previous exposure to resuscitation team training. 
Table 2. Example of a CREW scenario with technical and

Avoiding fixation error: avoiding premature diagnostic closure and anchoring when managing postintubation decompensation

Scenario: status asthmaticus (SA) with postintubation tension pneumothorax

Setting: high-fidelity simulation

Target team leader: senior EM resident

Technical objectives

Maximum medical therapy for SA

Intubation and mechanical ventilation in SA

Managing postintubation complications

Nontechnical objectives (focus for scenario debriefing)

Situational awareness: reassessment and reevaluation in a critically ill patient

Problem solving: approach to troubleshooting postintubation (e.g., the "DOPE" mnemonic)

CREW $=$ Crisis Resources for Emergency Workers; DOPE $=$ dislodged, obstructed, pneumothorax, equipment problem; EM = emergency medicine. nontechnical skills objectives

\section{Evaluating resident attitudes (Kirkpatrick Level 2)}

The Human Factors Attitude Survey (HFAS) is a 23item aviation-based training survey designed to measure attitudinal shifts regarding team behaviours. The HFAS is a modification of a scale developed by NASA to evaluate the effectiveness of early cockpit resource management training programs and has been validated in previous studies. ${ }^{21}$ Positive changes in HFAS scores are believed to reflect improved attitudes toward teambased behaviours such as communication, role clarity, and leadership during critical events. Residents completed the HFAS before the CREW II course and immediately after training. Individual and summed pre- and postcourse scores were compared using Wilcoxon signed rank tests with a $p<0.05$ threshold for statistical significance.

\section{Evaluating resident behaviour (Kirkpatrick Level 3)}

\section{Evaluating resident reaction to CREW II (Kirkpatrick Level 1)}

Following completion of the CREW II course, each resident completed a 17-item postcourse survey modified from Grogan and colleagues and designed to assess participant's reaction to the format, content, relevance, and impact of CREW II training. ${ }^{21}$ Responses were ranked on 5-point Likert scales with $1=$ strongly disagree, $3=$ neutral, and $5=$ strongly agree. Space was also provided for free-text comments and feedback. Descriptive statistics were used to summarize the responses.
Our primary outcome was the extent to which CREW II training influenced resident performance during a simulated team-based resuscitation. A subset of $10 \mathrm{EM}$ residents took part in a pre- and postcourse behavioural assessment, the goal of which was to objectively evaluate baseline and postcourse team leader performance using a previously validated behavioural rating scale (Figure 1). Participants were randomly assigned to one of two testing scenarios (TS1 or TS2) for baseline assessment 1 week prior to CREW II and returned for the second scenario 1 week following the course. TS1 and TS2 involved similar clinical objectives (managing a difficult airway during a resuscitation), whereas the context,

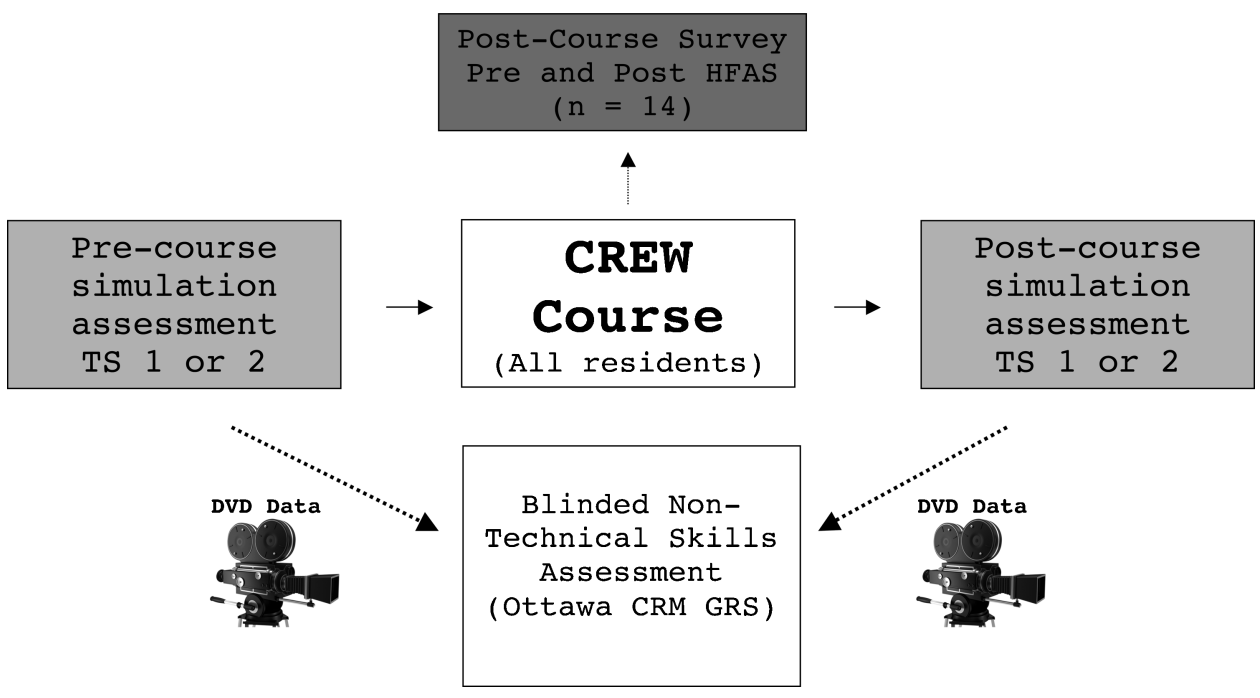

Figure 1. CREW II study design and evaluation schematic. Dotted arrows $=$ methods of evaluation CREW $=$ Crisis Resources for Emergency Workers; CRM = crisis resource management; GRS = Global Rating Scale; HFAS = Human Factors Attitude Survey; TS $=$ testing scenario. 
ambient conditions, and nontechnical elements were varied. Residents were asked to assume the role of physician team leader in both scenarios. Two local education experts with knowledge of resident training and simulation independently reviewed the testing scenarios to ensure that they were of similar difficulty and appropriate for EM resident participants. A team of three health care providers (two EM nurses and one respiratory therapist) was recruited as confederate participants for the testing scenarios. Confederates were trained to respond in a standardized fashion to isolate the behaviour of the team leader as the variable of interest. Pre- and postcourse testing scenarios were videotaped and the data converted to DVD format for subsequent analysis.

\section{Behaviour assessment: data outcome and analysis}

As this was a pilot study and without precedent in the literature to inform proper calculations, there was no a priori determination of sample size. The 10 residents who volunteered to participate in the pre/post behavioural assessment represent a convenience sample, with the goal of using the data obtained to inform sample size calculations for future studies. Two staff physicians with knowledge of simulation and CRM served as data reviewers and independently scored preand postcourse testing scenarios using the previously validated Ottawa CRM Global Rating Scale (GRS). The Ottawa GRS is a behavioural assessment tool consisting of six 7-point Likert scales with descriptive anchors corresponding to five core CRM domains (leadership, communication, situational awareness, problem solving, and resource use) and one overall team leader performance domain..$^{22}$ The Ottawa GRS has strong validity and interrater reliability for assessing CRM skills and team leader performance in a simulated environment across a variety of clinical scenarios and training levels. ${ }^{22}$ To calibrate the scoring process, reviewers discussed DVD recordings of CREW scenario pilot testing and how each variable should be scored on the Ottawa GRS. Reviewers were blinded to the resident's name and level of training and whether a given scenario was recorded prior to or following the CREW II course. Individual and total pre- and postcourse GRS scores were compared using paired $t$-tests. Interclass correlation coefficients (ICCs) were calulated to assess agreement between raters.

\section{RESULTS}

\section{Demographics}

Fourteen residents participated in the CREW II course and completed pre- and postcourse surveys, including eight junior residents (postgraduate year [PGY] 1-2) and six senior residents (PGY 3-5); 85.7\% of participants said that they were involved in between one and five ED resuscitations per month during their residency training. Although the majority of participants (92.8\%) had Advanced Cardiac Life Support (ACLS) or Advanced Trauma Life Support (ATLS) training, none had formal team training instruction prior to CREW II (Table 3).

\section{Resident reaction (Kirkpatrick Level 1)}

Fourteen residents participated in the CREW II course and completed the postcourse survey. Overall, participant assessment of the quality, relevance, and potential impact of training was highly positive. Residents found the high-fidelity scenarios to be more realistic and easier to interact with compared to the low-fidelity setup. The great majority of participants $(85.7 \%)$ agreed or strongly agreed with the statement "The crisis management knowledge learned from this course will be helpful in my practice" and that CREW II training has the potential to increase safety and quality of care and reduce errors (92.8\%); 78.6\% agreed or strongly agreed with the statement "This training will change the way I do things"; and $92.8 \%$ believed that the CREW II

\begin{tabular}{|c|c|}
\hline Characteristic & $n(\%)$ \\
\hline \multicolumn{2}{|l|}{ Postgraduate year } \\
\hline $1-2$ & $8(57.1)$ \\
\hline $3-5$ & $6(42.9)$ \\
\hline \multicolumn{2}{|c|}{ Resuscitation training } \\
\hline ACLS & $13(92.8)$ \\
\hline ATLS & 2 (14.3) \\
\hline Team training & $0(0)$ \\
\hline \multicolumn{2}{|c|}{ Resuscitations per month } \\
\hline 0 & $1(7.1)$ \\
\hline $1-5$ & $12(50.0)$ \\
\hline $6-10$ & $1(7.1)$ \\
\hline $11-15$ & $0(0)$ \\
\hline$>15$ & $0(0)$ \\
\hline
\end{tabular}


course would be suitable for refresher training, with $100 \%$ of respondents endorsing interdisciplinary team training as a preferred format. Feedback collected in the free-text section was clustered around two themes: 1) shorten the length of simulation-based instruction and 2) include interprofessional training.

\section{Resident attitudes (Kirkpatrick Level 2)}

Fourteen residents completed both pre- and postcourse HFASs. Although there was a general trend toward improved postcourse scores, only the question "During any procedure or shift, and in response to unplanned or unbriefed contingencies, the team leader should verbalize plans for procedures and should be sure that the information is understood and acknowledged by all team members" demonstrated a statistically significant positive change $(p=0.0313)$. Summed pre- and postcourse scores also showed a trend toward improved attitudes, although this was not statistically significant $(p=0.210)$.

\section{Resident behaviour (Kirkpatrick Level 3)}

Of the 10 residents who participated in the behavioural assessment, 2 did not complete the postcourse assessment. Although positive trends were consistently observed in all six categories of the Ottawa GRS, none were found to be statistically significant from pre- to postcourse (Figure 2). Similar nonsignificant trends toward improved overall performance were found in differences in summed pre- and postcourse scores $(p=$ 0.16 ). The ICC was 0.71 , indicating good interrater agreement. ${ }^{23}$

\section{DISCUSSION}

HROs in aviation, the military, and nuclear power are characterized by a low incidence of adverse events despite an ongoing potential for disaster. HROs rely heavily on human factors theory and team training as countermeasures to error for both routine operations and critical events. In aviation, high-fidelity simulators are used to instruct flight teams on crew resource management, emphasizing communication, crossmonitoring, resource use, situational awareness, and problem solving. ${ }^{24}$ Crew resource management is a mandatory component of flight crew training and commercial carrier certification and is credited in part for the steady decline in in-flight catastrophes over the past three decades. ${ }^{24}$

Integrating nontechnical skills and CRM training into the patient safety culture has been limited in part by the lack of effective methods for evaluating the

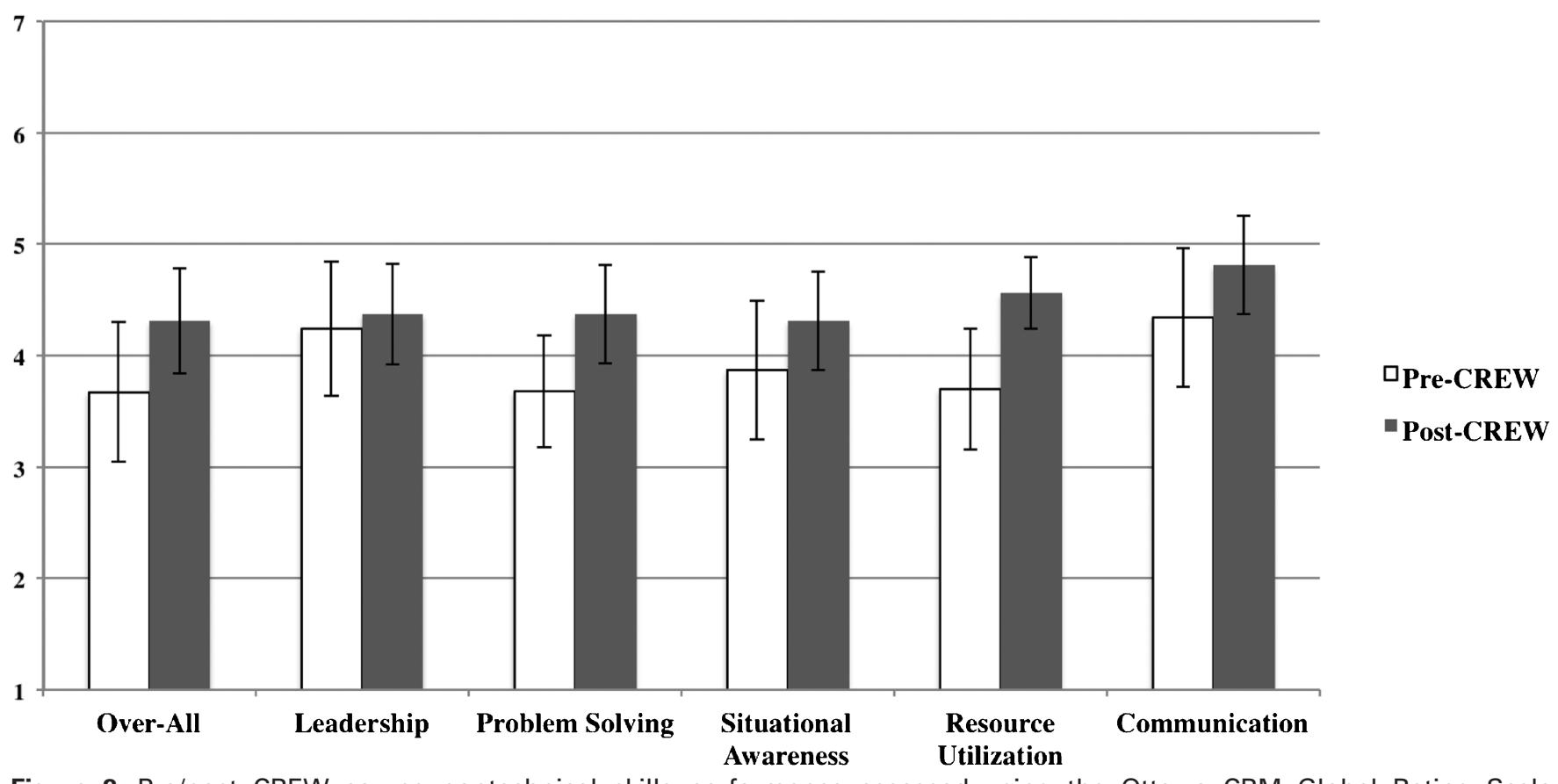

Figure 2. Pre/post CREW course nontechnical skills performance assessed using the Ottawa CRM Global Rating Scale (maximum score $=7$, minimum score $=1$ ). Error bars represent standard error of the means. CREW $=$ Crisis Resources for Emergency Workers. 
impact of instruction on both individual and team behaviours. In 2003, Reznek and colleagues examined the responses to and feasibility of a simulation-based EM CRM curriculum for postgraduate trainees. ${ }^{14}$ Although the responses were highly favourable, it is difficult to ascertain to what extent these positive attitudes translated to improved knowledge or performance. Previous studies have examined EM team performance in situ, notably Morey and colleagues in 2002 (the MedTeams project) and Shapiro and colleagues in $2004 .{ }^{25,26}$ In both cases, the researchers found a positive impact on error rates and team performance after nontechnical skills instruction.

To our knowledge, the CREW II study represents the first attempt at the systematic design and multilevel assessment of a CRM curriculum for EM residents that includes observable behaviours as the primary outcome, as suggested by Kirkpatrick ${ }^{16}$ and emphasized in the high-risk industry and medical safety literature. We chose to target the first three levels of the Kirkpatrick typology (attitudes, learning, and behaviour), recognizing that measuring the effects on in situ performance would require a larger sample size and prolonged observation, both of which were beyond the scope of this pilot study. Achieving lasting, meaningful organizational change is a slow and incremental process in which simulation-based team training can play an important role. The methodology described in the CREW II study provides a "road map" for the design, implementation, and multilevel assessment of simulationbased training programs as a step toward demonstrating transfer of training, with roots in both the literature and formal a priori team task analysis.

In 2005, the Royal College of Physicians and Surgeons of Canada (RCPSC) launched CanMEDS, a competency-based framework for medical education. ${ }^{27}$ Since its introduction, there has been a need to develop valid and reliable methods of instruction and assessment of the seven CanMEDS roles for residents. Simulationbased CRM training provides an opportunity for focused instruction, feedback, and assessment on the communicator, collaborator, and manager roles in a manner that is consistent and reproducible. Our findings demonstrate that the CREW II curriculum is feasible and well received by residents and provides a valid and reliable strategy for teaching and evaluating these key CanMEDS competencies during critical events.

Our primary outcome was the impact of training on observed behaviour and performance during simulated resuscitations. Although there was a trend toward improved postcourse scores on the Ottawa GRS, this did not reach statistical significance. One possible explanation is that our behavioural assessment may have been underpowered to detect a difference between pre- and postcourse scores. Recruiting adequate sample sizes is a common challenge for medical education studies and speaks to the need for multisite collaboration.

The Ottawa GRS appears to be an appropriate choice as a behavioural assessment tool for EM residents in this context. The ICC we found of 0.71 suggests good interrater agreement between our blinded reviewers and represents an improvement over the agreement observed in the original derivation and validation of the tool, demonstrating the feasibility and translational application of the Ottawa GRS in a new environment while also independently validating this measurement scale. This finding has implications for EM educators in search of a reliable tool for assessing resident team-based skills or providing structured feedback on performance.

There was a trend toward improvement in pre- and postcourse attitude assessment scores using the HFAS and a statistically significant improvement in 1 of the 23 items on the inventory. Based on a $p<0.05$ level of significance for analysis, it is highly conceivable that this effect arose due to chance. It is notable, however, that this one category, where we found a significant positive change related to team briefing and communication skills, received particular emphasis during training. Our focus on effective communication and briefing was deliberate because errors in communication are believed to be among the most prevalent during critical events, and our team task analysis identified communication as a priority for EM-focused CRM training. ${ }^{18}$

The results of our postcourse survey suggest that residents find CREW II training to be enjoyable, realistic, and relevant to their training and practice, which is consistent with survey data from previous studies. ${ }^{14}$ Residents preferred the high-fidelity environment to the low-fidelity setup, suggesting that this might be the most appropriate method of instruction for future EM-focused CRM endeavours. Including a low-fidelity setup in the CREW course achieved the practical goal of maximizing the opportunity for deliberate practice within the constraints of a singleday course, but the low-fidelity scenarios probably lacked the necessary degree of realism required to achieve a sufficient degree of participant "buy-in." 
Finally, course participants were uniformly enthusiastic to engage in a truly interdisciplinary team training exercise. Although role-playing is a helpful and convenient way to reproduce multimember teams in a simulated environment, future work in this area should include additional EM personnel, in particular other resuscitation team members from nursing and respiratory therapy. Quantifying the impact of interdisciplinary versus same-discipline team training is a topic of great interest for simulation-based educators and should be explored in the context of larger, interprofessional team training studies.

\section{LIMITATIONS}

The impact of precourse assessment on performance is well recognized, and in this pre/post design, it is difficult to isolate the effect of CREW II training from learning that may have occurred as a result of baseline testing. Previous studies have found that no significant learning occurs in simulation-based scenarios not paired with a focused debriefing session. ${ }^{22,28,29}$ In the CREW II study, the precourse testing scenarios were not debriefed; thus, the amount of learning that can be attributed to the pretest is probably negligible.

Pre- and postcourse assessment was separated by 2 weeks, making the impact of additional clinical experience on learning and postcourse scores likely small. Given the short interval between pre- and postcourse, it is difficult to know the extent to which performance improved or decayed over time. Future studies should include prospective, longitudinal followup posttraining to assess issues of nontechnical skills retention and decay and to define intervals for refresher training.

We chose to examine the team leader as the unit of analysis in pre- and postcourse testing using the Ottawa GRS and to standardize the performance of the team by using trained confederates. Future studies might benefit from examining the performance of interdisciplinary teams before and after training using scales that assess global team performance, such as the Mayo High Performance Teamwork Scale. ${ }^{30}$

\section{CONCLUSION}

The CREW II study represents a first effort at multilevel assessment for a simulation-based CRM training program for Canadian EM residents. Our findings indicate that EM residents find simulation-based CRM instruction to be useful, effective, and highly relevant to their practice. Trends toward improved performance and attitudes may have arisen because our study was underpowered to detect a difference. Future efforts should focus on interdisciplinary training and recruiting a larger sample size.

Acknowledgements: We thank Dr. Vicki LeBlanc, $\mathrm{PhD}$, for her editorial assistance and the simulation team members and confederates at the Canadian Simulation Centre for Human Performance and Crisis Management Training at Sunnybrook Health Sciences Centre.

Competing interests: Funding was provided by the Canadian Association of Emergency Physicians.

\section{REFERENCES}

1. Croskerry P. Cognitive forcing strategies in clinical decisionmaking. Ann Emerg Med 2003;41:110-20, doi:10.1067/ $\underline{\text { mem.2003.22. }}$.

2. Chisholm C, Collison E, Nelson D, et al. Emergency department workplace interruptions: are emergency physicians "interruption-driven" or "multitasking"? Acad Emerg Med 2000;7:1239-43, doi:10.1111/j.1553-2712.2000.tb00469.x.

3. Kohn L, Corrigan J, Donaldson JE. To err is human: building a safer health system. Washington (DC): National Academy Press; 1999.

4. Williamson J, Webb R, Sellen A, et al. Human failure: an analysis of 2000 incident reports. Anesth Intensive Care 1993; 21:678-83.

5. LeBlanc V. The effects of acute stress on performance: implications for health professions education. Acad Med 2009; 84(10 Suppl):S25-33, doi:10.1097/ACM.0b013e3181b37b8f.

6. Driskell J, Salas E. Does stress lead to a loss of team perspective? Group Dynamics 1999;3:291-302, doi:10.1037/ 1089-2699.3.4.291.

7. Driskell J, Salas E. Group decision making under stress. 7 Appl Psychol 1991;76:473-8, doi:10.1037/0021-9010.76.3.473.

8. Gaba D, Howard S, Fish K. Crisis management in anesthesiology. New York: Churchill Livingstone Publishers; 1994.

9. Helmreich R. On error management: lessons from aviation. BMF 2000;320:781-5, doi:10.1136/bmj.320.7237.781.

10. Ziv A, Wolpe P, Small S, et al. Simulation-based medical education: an ethical imperative. Acad Med 2003;78:783-8, doi:10.1097/00001888-200308000-00006.

11. Ericsson K, Krampe R, Tesch-Romer C. The role of deliberate practice in the acquisition of expert performance. Psychol Rev 1993;100:363-406, doi:10.1037/0033-295X.100. 3.363 .

12. Gaba D, Howard S, Fish K. Simulation-based training in anesthesia crisis resource management (ACRM): a decade of experience. Simul Gaming 2001;32:175-93, doi:10.1177/ $\underline{104687810103200206 .}$ 
13. Hunt E, Shilkofski N, Stavroudis T, et al. Simulation: translation to improved team performance. Anesthesiol Clin 2007;25:301-19, doi:10.1016/j.anclin.2007.03.004.

14. Reznek M, Smith-Coggins R, Howard S, et al. Emergency Medicine Crisis Resource Management (EMCRM): pilot study of a simulation-based crisis management course for emergency medicine. Acad Emerg Med 2003;10:386-9, doi:10.1111/j.1553-2712.2003.tb01354.x.

15. Burke C, Salas E, Wilson-Donnelly K, et al. How to turn a team of experts into an exert medical team: guidance from the aviation and military communities. Qual Saf Health Care 2004;13:96-104, doi:10.1136/qshc.2004.009829.

16. Kirkpatrick D. Evaluation of training In: Craig R, editor. Training and development bandbook: a guide to buman resources development. New York: McGraw-Hill; 1976. p. 18.1-.27.

17. Salas E, Burke S, Bowers C, et al. Team training in the skies: does crew resource management (CRM) training work? Hum Factors 2001;43:641-74, doi:10.1518/001872001775870386.

18. Hicks C, Bandiera G, Denny C. Building a crisis resource management course for emergency medicine, phase 1 : results from an interdisciplinary needs assessment survey. Acad Emerg Med 2008;15:1136-43, doi:10.1111/j.1553-2712. 2008.00185.x.

19. TuPASS scenario script. 2008. Available at: http://www.tupass. de/downloads/TuPASS_Scenario_Script.doc (accessed July 20, 2008).

20. Society for Acacemic Emergency Medicine (SAEM) simulation case library. 2007. Available at: http://www.emedu.org/ (X(1)S(h0e1b345v53cwqigtmcvew55))/simlibrary/default.aspx? AspxAutoDetectCookieSupport $=1$ (accessed July 20, 2008).

21. Grogan E, Styles R, France D, et al. The impact of aviationbased teamwork training on the attitudes of health care professionals. 7 Am Coll Surg 2004;199:843-8, doi:10.1016/ i.jamcollsurg.2004.08.021.

22. Kim J, Neilipovitz D, Cardinal P, et al. A pilot study using high-fidelity simulation to formally evaluate performance in the resuscitation of critically ill patients: The University of Ottawa Critical Care Medicine, High-Fidelity Simulation, And Crisis Resource Management I Study. Crit Care Med 2006;34:2167-74, doi:10.1097/01.CCM.0000229877.45125. CC.

23. Shrout P, Fleiss J. Interclass correlations: uses in assessing rater reliability. Psychol Bull 1979;86:420-8, doi:10.1037/ 0033-2909.86.2.420.

24. Helmreich R, Merritt A, Wilhelm J. The evolution of crew resource management training in commerical aviation. Int 7 Aviat Psychol 1999;9:19-32, doi:10.1207/s15327108ijap0901_2.

25. Morey J, Simon R, Jay G, et al. Error reduction and performance improvement in the emergency department through formal teamwork training: evaluation results of the MedTeams Project. Health Serv Res 2002;37:373-83, doi: 10.1111/1475-6773.01104.

26. Shapiro M, Morey J, Small S, et al. Simulation based teamwork training for emergency department staff: does it improve clinical team performance when added to an existing didactic teamwork curriculum? Qual Saf Health Care 2004;13:417-21, doi:10.1136/qshc.2003.005447.

27. Royal College of Physicians and Surgeons of Canada. About CanMEDS. Available at: http://rcpsc.medical.org/canmeds/ about_e.php (accessed March 1, 2008).

28. Fanning R, Gaba D. The role of debriefing in simulationbased learning. Simul Healthc 2007;2:115-25, doi:10.1097/ SIH.0b013e3180315539.

29. Salvodelli G, Naik V, Park J, et al. Value of debriefing during simulated crisis management: oral versus videoassisted oral feedback. Anesthesiology 2006;105:279-85, doi: 10.1097/00000542-200608000-00010.

30. Malec J, Torsher L, Dunn W, et al. The Mayo High Performance Teamwork Scale: reliability and validity for evaluating key crew resource management skills. Simul Healthc 2007;2:4-10, doi:10.1097/SIH.0b013e31802b68ee. 